\title{
Patterns of breathlessness and associated consulting behaviour: results of an online survey
}

\author{
Amany F Elbehairy, ${ }^{\circledR 1,2}$ Jennifer K Quint, ${ }^{3}$ Judith Rogers, ${ }^{4}$ Michael Laffan, ${ }^{4}$ \\ Michael I Polkey, 'Nicholas S Hopkinson ${ }^{1}$
}

\begin{abstract}
- Additional material is published online only. To view please visit the journal online (http://dx.doi.org/10.1136/ thoraxjnl-2018-212950).

${ }^{1}$ National Heart and Lung Institute, Imperial College, London, UK

${ }^{2}$ Faculty of Medicine, Alexandria University, Alexandria, Egypt ${ }^{3}$ Respiratory Epidemiology, Occupational Medicine and Public Health, Imperial College London, London, UK ${ }^{4}$ British Lung Foundation, London, UK
\end{abstract}

\section{Correspondence to} Dr Nicholas S Hopkinson, National Heart and Lung Institute, Royal Brompton and Harefield NHS Foundation Trust and Imperial College, London SW3 6NP, UK;

n.hopkinson@ic.ac.uk

Received 10 December 2018 Revised 27 February 2019 Accepted 11 March 2019 Published Online First 8 April 2019

\section{Check for updates}

(c) Author(s) (or their employer(s)) 2019. No commercial re-use. See rights and permissions. Published by BMJ.

To cite: Elbehairy AF, Quint JK, Rogers J, et al. Thorax 2019;74:814-817.

\section{ABSTRACT}

The online British Lung Foundation Breath Test provides an opportunity to study the relationship between breathlessness, common sociobehavioural risk factors and interaction with healthcare. We analysed data from 356799 responders: $71 \%$ were $\geq 50$ years old and $18 \%$ were smokers. 20\% reported limiting breathlessness (Medical Research Council breathlessness score $\geq 3$ ), and the majority of these (85\%) worried about their breathing; of these, $29 \%$ had not sought medical advice. Of those who had, 58\% reported that the advice received had not helped their breathlessness. Limiting breathlessness was associated with being older, physically inactive, smoking and a higher body mass index. These data suggest a considerable unmet need associated with breathlessness as well as possibilities for intervention.

\section{INTRODUCTION}

Breathlessness is a common symptom, particularly in older people, and can be due to lack of physical fitness related to physical inactivity and body habitus, as well as cardiac or respiratory disease. ${ }^{1}$ Anxiety can aggravate other causes of breathlessness or itself be the cause. The breathing SPACE (smoking, pulmonary disease, anxiety, cardiac disease, exercise level) framework has been proposed as a systematic way to approach conditions associated with breathlessness. ${ }^{2}$ Breathlessness is often dismissed as a normal part of ageing, leading to late presentation and/or delayed diagnosis. ${ }^{3}$ In clinical practice, respiratory and cardiovascular diseases account for approximately two-thirds of presentations with exertional breathlessness. ${ }^{4}$

The British Lung Foundation (BLF) developed an online survey tool, the 'BLF Breath Test', that members of the public could use to assess their breathing and possible contributing factors. Based on individual responses, subjects were given tailored advice. Survey responses provide an opportunity to analyse the relationship between breathlessness, common sociobehavioural risk factors and experience of healthcare.

\section{Study design}

The online BLF Breath Test was developed through an extensive stakeholder-reviewed process (https:// breathtest.blf.org.uk/) and included 10 questions about demographics, physical activity, smoking history and Medical Research Council (MRC) Breathlessness Scale (online supplementary table E1). Advertising, including via social media, was used to invite members of the public to complete the test (January 2016-April 2018). Based on individual responses, tailored advice was given (eg, lifestyle changes, smoking cessation, weight reduction, or visiting their general practitioner) (online supplementary table E2). They were also asked whether they agreed to be contacted for a follow-up survey to assess the impact of taking the test. If so, a follow-up survey was sent by email roughly 1 year after the initial test (online supplementary table E3). To enhance accuracy, only those who said they recalled taking the Breath Test were allowed to continue with the survey; however, the numbers were too low to be presented, and details are provided in the online supplementary file.

\section{Statistical analysis}

Data were analysed using SPSS V.24. Descriptive statistics were used to present the demographic data. Comparisons of proportions were done using $\chi^{2}$ test. Statistical significance was set at $\mathrm{p}<0.05$.

Limiting breathlessness was defined as a score of $\geq 3$ out of 5 on the MRC scale, and 'non-breathless' as a score of 1 or $2 .^{5}$ Physical inactivity was defined as doing less than $20 \mathrm{~min}$ of daily physical activity.

\section{RESULTS}

There were 365043 responses entered, and 356 799 were included in the current analysis after excluding missing or wrong data (figure 1, online supplementary file). Of the total sample, $71 \%$ were aged $\geq 50$ years, $18 \%$ current smokers, $68 \%$ had body mass index $(\mathrm{BMI}) \geq 25 \mathrm{~kg} / \mathrm{m}^{2}$ and $35 \%$ were physically inactive (table 1 , online supplementary figure E1-E4).

Twenty per cent $(n=71634)$ of the whole sample reported limiting breathlessness, and of these $85 \%$ $(n=61$ 196) said that they worried about getting out of breath, but of these $29 \%(n=17747)$ had not sought medical advice. Among those who had sought medical advice $(n=43449), 58 \% \quad(n=25$ 200) reported that this had not helped with their breathlessness (figure 1).

Compared with non-breathless people, those with limiting breathlessness were more likely to be $>60$ years (mean percentage difference [95\% CI] 17.7 [17.3 to 18.1$])$, current smokers (2.6 [2.2 to 2.9]) and physically inactive (21.7 [21.3 to 22.1]) (all $\mathrm{p}<0.0001)$ (figure 2). In addition, those with limiting breathlessness had a higher BMI compared with non-breathless people (31.2 \pm 7.6 vs $27.8 \pm 5.7$ $\mathrm{kg} / \mathrm{m}^{2}[$ mean $\left.\pm \mathrm{SD}], \mathrm{p}<0.0001\right)$.

Follow-up survey response rate was low (8\%), so results are presented online only for information (online supplementary figures E5-E9, table E4). 


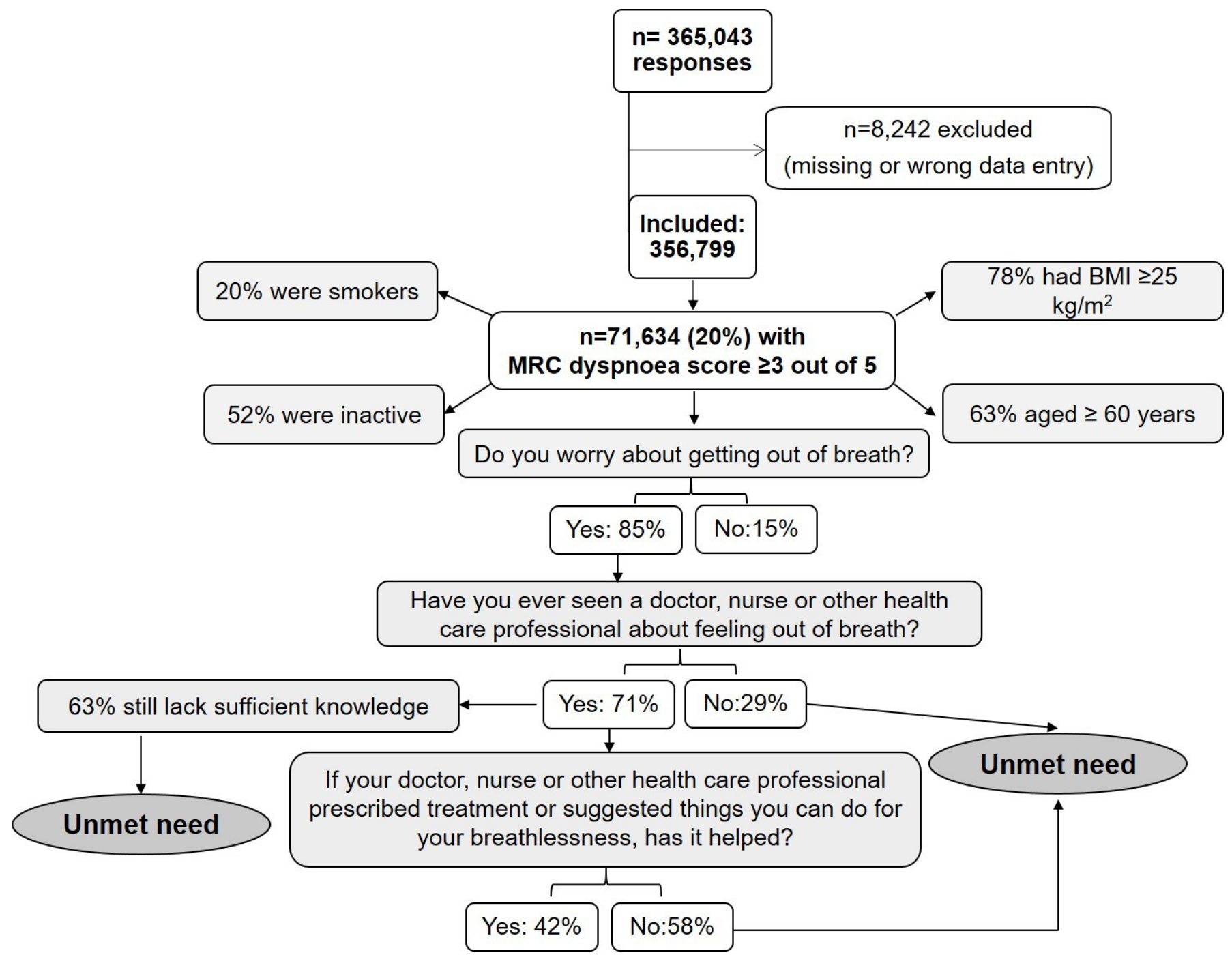

Figure 1 Flow chart of responses to the British Lung Foundation online Breath Test. Note that 'unmet needs' among people suffering from limiting breathlessness (MRC breathlessness score $\geq 3$ out of 5) represent (1) those who did not seek medical advice despite their having significant symptoms, and (2) those who had sought medical advice but still lacked sufficient knowledge about their symptoms or felt that the advice they received had not helped their breathlessness. BMI, body mass index; MRC, Medical Research Council.

\section{DISCUSSION}

The principal finding of this large survey is that there is substantial unmet need related to breathlessness, with individuals who have limiting breathlessness not seeking healthcare, and furthermore a substantial number who had done so reporting that they had not found it effective.

The study confirms the importance of established factors reported to be associated with breathlessness, including obesity, physical inactivity, smoking and ageing. ${ }^{67}$

While 20\% of our sample reported breathlessness, this is higher than a previous population survey results that reported a prevalence of $8.9 \%$ in a smaller sample $(n=5480){ }^{8}$ As previously described in epidemiological studies, ${ }^{1}$ about $60 \%$ of those presenting with limiting breathlessness (MRC dyspnoea score of $3-5$ ) in our sample were aged $\geq 60$ years.

\section{Significance of the findings}

Although the majority (85\%) of subjects with limiting breathlessness said that they worried about getting out of breath, 29\% of those had not sought medical advice regarding the symptom. Moreover, more than half of those who sought medical advice said that the advice received had often not helped with their breathlessness (figure 1). This collectively represents a considerable unmet need around breathlessness. This consists of both 'unexpressed demand' (ie, people who have healthcare needs but who are not aware of them, or who choose not to seek healthcare) and 'expressed demand that is sub-optimally met'. These results should provide a prompt to examine the problems with accessing healthcare services and to improve public awareness about breathlessness as a symptom that requires explanation.

Collectively, our data show that limiting breathlessness is a common problem affecting mainly older people, a demand that is currently suboptimally met and requires further attention with the aim to timely diagnose and treat patients and improve healthcare services. Low access to services by breathless people may be due to the nature of the symptom itself, which can have slow and surreptitious onset. ${ }^{9}$ Importantly, effective evidence-based interventions for limiting breathlessness exist ${ }^{1011}$ but they are often underutilised in primary and secondary care. 
Table 1 Subject characteristics: BLF online Breath Test $(n=356$ 799)

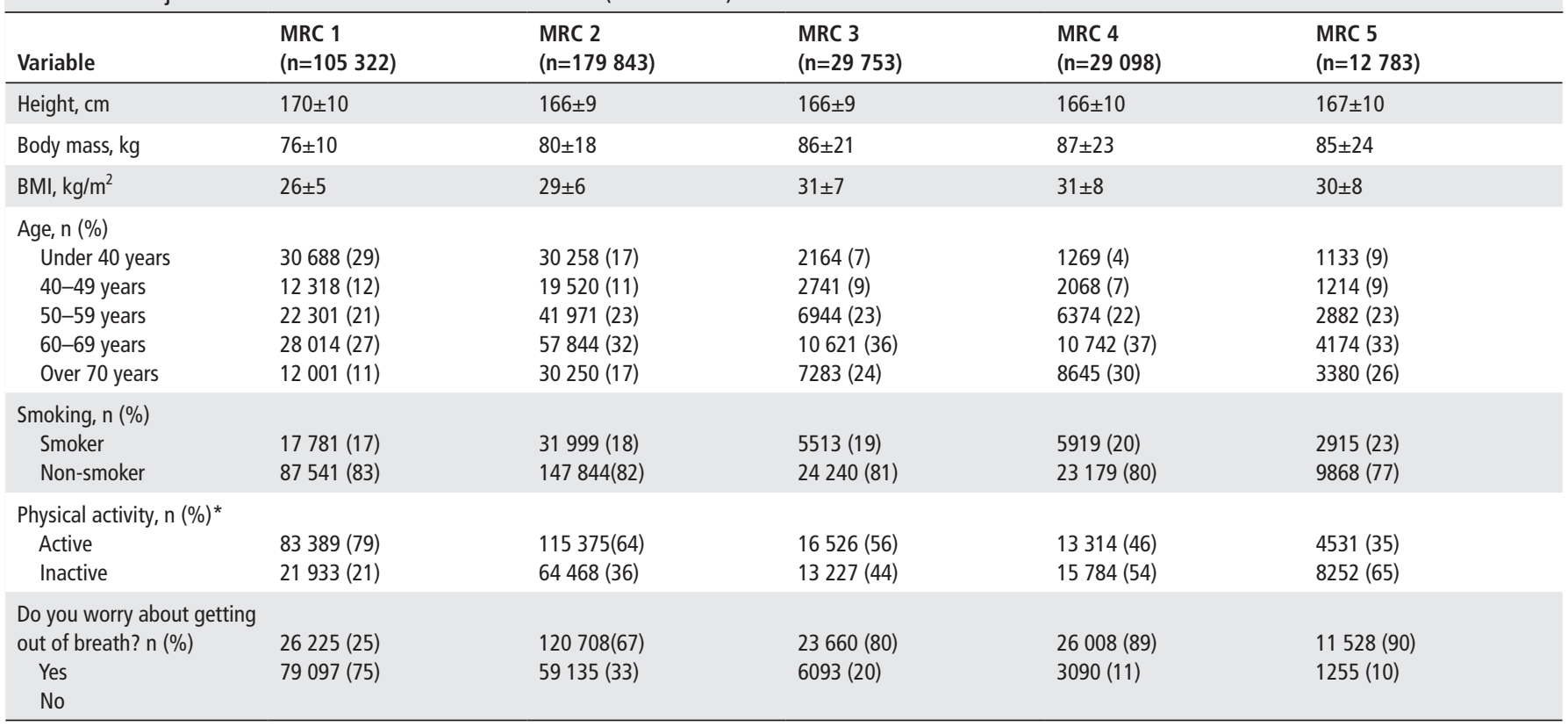

Values are mean \pm SD for height, weight and BMI and $\mathrm{n}(\%)$ of total subjects for other variables.

* Physical activity assessed as doing at least $20 \mathrm{~min}$ a day of any of the following activities: walking, cycling, gardening or anything else that makes the subject breathe faster. BLF, British Lung Foundation; BMI, body mass index; MRC, Medical Research Council.

\section{Strengths and limitations}

These data represent a large number of breathless individuals; however, taking the BLF Breath Test survey was not part of a systematic sampling approach, so caution is needed when considering its applicability to the general population. The online design of the study did allow participation by those who, for example, were unable to leave their house.

After completing the Breath Test, people received advice tailored to their responses. The follow-up survey was intended to evaluate the impact of these (online supplementary file).

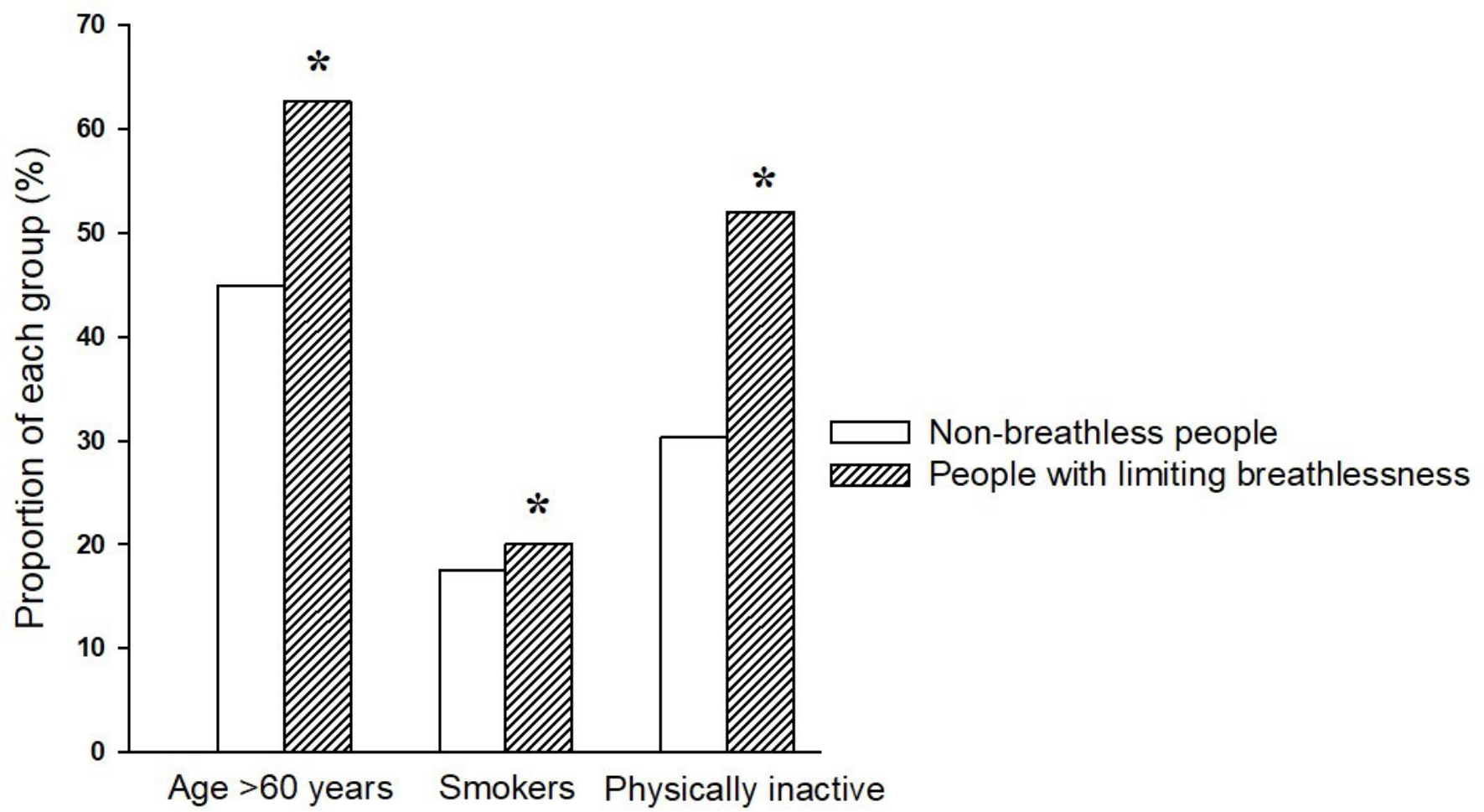

Figure 2 Comparison of proportions of being older ( $>60$ years), current smoker and physically inactive between people with limiting breathlessness (MRC breathlessness score $\geq 3$ out of $5, n=71634$ ) and those who were non-breathless (MRC breathlessness score of 1 or $2, n=258165$ ). Values are percentage of subjects within each group. ${ }^{*} \mathrm{P}<0.05$, people with limiting breathlessness versus non-breathless individuals. Physically inactive: those who reported not doing at least 20 min of daily activities. MRC, Medical Research Council. 
Unfortunately, the response rate was too low to allow confident conclusions to be drawn. Nevertheless, it is encouraging that $33 \%$ reported that they had made some lifestyle changes, for example, increasing their exercise level or improving their dietary habits. Interestingly, $6 \%$ of subjects successfully quit smoking after taking the test, while $3 \%$ had tried to quit but failed. These data support the notion that the BLF Breath Test can reach individuals who are not currently known to orthodox health services and beneficially change behaviour. As such the data should be considered hypothesis-generating.

\section{CONCLUSION AND FUTURE RESEARCH}

Data from this large survey of breathlessness suggest considerable unmet need, both unexpressed demand and expressed demand, that is suboptimally met. Apart from ageing, the factors associated with breathlessness are potentially modifiable, suggesting that the BLF online Breath Test could have a role in prompting useful interventions. The impact of tailored advice, using online surveys, on breathlessness might be the scope for future studies. Including questions on subjective aspects of breathlessness in future similar studies may help to contextualise the findings.

\section{Twitter Follow NSH at @COPDdoc}

Contributors The authors meet the criteria for authorship as recommended by the International Committee of Medical Journal Editors. All the authors played a role in the content and writing of the manuscript. In addition, NSH provided the original idea for the study. JR and ML collected the data. AFE performed the data analysis and prepared it for presentation. JKQ and MIP had input in writing up the final manuscript.

Funding AFE received financial support from the British Academy of Medical Sciences through the Daniel Turnberg UK/Middle East Travel Fellowship scheme and the European Respiratory Society Short-Term Fellowship.
Competing interests None declared.

\section{Patient consent for publication Not required.}

Ethics approval The present analysis of the anonymised data collected was approved by the BLF information governance process. External ethical approval was deemed not necessary.

Provenance and peer review Not commissioned; externally peer reviewed.

\section{REFERENCES}

1 van Mourik Y, Rutten FH, Moons KGM, et al. Prevalence and underlying causes of dyspnoea in older people: a systematic review. Age Ageing 2014;43:319-26.

2 Hopkinson NS, Baxter N, London Respiratory Network. Breathing SPACE-a practical approach to the Breathless patient. NPJ Prim Care Respir Med 2017:27.

3 Jones RCM, Price D, Ryan D, et al. Opportunities to diagnose chronic obstructive pulmonary disease in routine care in the UK: a retrospective study of a clinical cohort. Lancet Respir Med 2014;2:267-76

4 Pratter MR, Curley FJ, Dubois J, et al. Cause and evaluation of chronic dyspnea in a pulmonary disease clinic. Arch Intern Med 1989;149:2277-82.

5 Fletcher CM. Standardised questionnaire on respiratory symptoms: a statement prepared and approved by the MRC Committee on the aetiology of chronic bronchitis (MRC breathlessness Score). BMJ 1960;2:1665

6 Johnson MJ, Bowden JA, Abernethy AP, et al. To what causes do people attribute their chronic breathlessness? A population survey. J Palliat Med 2012;15:744-50.

7 Milne JS, Williamson J. Respiratory symptoms and smoking habits in older people with age and sex differences. Respiration 1972;29:359-70.

8 Currow DC, Plummer JL, Crockett A, et al. A community population survey of prevalence and severity of dyspnea in adults. J Pain Symptom Manage 2009;38:533-45

9 Gysels M, Higginson IJ. Access to services for patients with chronic obstructive pulmonary disease: the invisibility of breathlessness. J Pain Symptom Manage 2008:36:451-60.

10 O'Donnell DE, Webb KA, Harle I, et al. Pharmacological management of breathlessness in COPD: recent advances and hopes for the future. Expert Rev Respir Med 2016;10:823-34.

11 Booth S, Moffat C, Burkin J, et al. Nonpharmacological interventions for breathlessness. Curr Opin Support Palliat Care 2011;5:77-86. 